\title{
The Complete Mitochondrial Genome of the Donganyellow Chicken and Its Phylogenetic Analyses
}

\section{Author(s)}

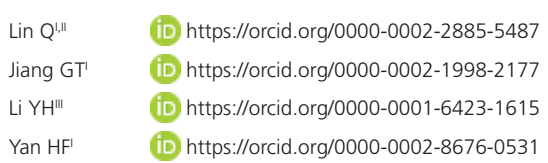

(iD) https://orcid.org/0000-0002-8676-0531

Research Department of Animal Nutrition and Poultry, Hunan Institute of Animal and Veterinary Science, Changsha, PR China

" Institute of Bast Fiber Crops, Chinese Academy of Agricultural Sciences, Changsha, PR China

II College of Animal Science and Technology, Hunan Agricultural

\section{-Mail Address}

Corresponding author e-mail address Hai-Feng Yan

Hunan Institute of Animal and Veterinary Science, No. 8 Changlang Road,

Changsha City, Hunan Province, PR China. Email: hfyan2005@163.com

\section{-Keywords}

Gallus gallusdomesticus, Donganyellow chicken, mitochondrial, phylogenetic analyses.

\begin{abstract}
Donganyellow chicken (Gallus gallusdomesticus, DYC) is one of the famous native breeds of Hunan province in China. It is the first time that the complete mitochondrialgenome sequence of DYC was reported. The total length of the mtDNA is $16,786 \mathrm{bp}$. It contains 22 transfer RNA genes, 2 ribosomal RNA genes, 13 protein-coding genes and 1 D-loop region. The overall composition of the mtDNA is $30.27 \%$ for $\mathrm{A}, 23.74 \%$ for T, $32.50 \%$ for C and $13.49 \%$ for $\mathrm{G}$. Phylogenetic analyses using $\mathrm{N}-\mathrm{J}$ computational algorithms showed that the analyzed20Galliformes species are divided into three major clades: Phasianidae, Numidiidae and Odontophoridae. In addition, our work confirmed that DYCand Taoyuan chickenhave a closegenetic relationship with fellow tribal members Xuefeng black-boned chicken and Huang Lang chicken. This work will provide an important data set for the study in genetic mechanism of chicken in Hunan province.
\end{abstract}

\section{INTRODUCTION}

Donganyellow chicken (Gallus gallusdomesticus, DYC), is one of the important indigenous protected breeds of chicken in Hunan Province, which has been bred in Dongan county for hundreds of years. The features of DYC is strong adaptability, good stress resistance and good meat quality (Chen, 2013). In addition, domestic chickens (Gallus gallusdomesticus) play the keyrole in the agricultural and economic sectors in Hunan Province. There are numerous domestic chicken breeds in Hunan Province including Taoyuan chicken (TYC), Huang Lang chicken (HLC), Xuefeng black-boned chicken (XBC) and DYC. However, a better characterization of the complete mitochondrial genome and genetic diversity of four domestic chicken breeds mentioned above is in urgent need to increase the conservational application for these four species.

\section{MATERIALS AND METHODS}

\section{Determination and analysis of the complete mitochondrial genome sequence of DYC}

This study determined complete mitochondrial DNA sequence of DYC, which has been registered in GenBank under accession number KM886937. The chicken was farmed at Hunan Dongan Chicken Technology Co., Ltd. (Yongzhou City, Hunan Province, China). Mitochondrial DNA of DYC was extracted using the EasyPure Kit of Genomic DNA (Transgen Biotech, Beijing, China) according to its instruction manual. PCR was carried out to amplify the complete mitochondrial genome with 11 pairs of primers. PCR products of the Gel electrophoresis were purified by Gel Advanced ${ }^{\mathrm{TM}}$ Gel Extraction (Rich 
Biotech, Taiwan, China) and sequenced by BioSune Biotech (Shanghai, China). The mitochondrial DNA sequence was analyzed using DNAStar.Lasergene.v7.1 software, tRNA Scan-SE1.21 software and DOGMA software.

\section{Phylogenetic analysis}

Phylogenetic analysis was performed using the complete mitochondrial DNA sequences of $20 \mathrm{Galliformes}$. Each of the sequence dataset was aligned by ClustalXand analyzed by neighbor-joining $(\mathrm{N}-J)$ in MEGA 4.0, and bootstrap analysis was performed with 100 replications.

\section{RESULTS AND DISSCUSSION}

The total length of the mtDNA is $16,786 \mathrm{bp}$. It contains the typical structure, including 24 RNA genes, 13 protein-coding genes and 1 D-loop region as that of most other vertebrates (Lin et al. 2016a). The overall composition of the mtDNA was estimated to be $30.27 \%$ for $A, 23.74 \%$ for $T, 32.50 \%$ for $C$ and $13.49 \%$ for $\mathrm{G}$. All the protein initiation codons are ATG, except for COX1 which is GTG (Table 1). All the mtDNA genes were encoded on the heavy $(H)$ strand except for eight types of tRNA genes and ND6 gene. All these genes have15 spaces in the length of 1-9bpand

Table 1 - Organization of the mitochondrial genome of Dongan yellow chicken.

\begin{tabular}{|c|c|c|c|c|c|c|c|c|}
\hline \multirow{2}{*}{ Gene name } & \multicolumn{2}{|c|}{ Position } & \multirow{2}{*}{ Size } & \multicolumn{2}{|c|}{ Codon } & \multirow{2}{*}{ Anti-codon } & \multirow{2}{*}{ Strand } & \multirow{2}{*}{ Space/overlap ${ }^{+}$} \\
\hline & Start & End & & Start & Stop & & & \\
\hline D-loop & 1 & 1232 & 1232 & & & & & \\
\hline tRNA & 1233 & 1302 & 70 & & & GAA & $\mathrm{H}$ & \\
\hline $12 S$ rRNA & 1303 & 2277 & 975 & & & & $\mathrm{H}$ & \\
\hline$t R N A^{v a l}$ & 2278 & 2350 & 73 & & & TAC & $\mathrm{H}$ & \\
\hline $16 S$ rRNA & 2351 & 3973 & 1623 & & & & $\mathrm{H}$ & \\
\hline tRNA & 3974 & 4047 & 74 & & & TAA & $\mathrm{H}$ & \\
\hline ND1 & 4057 & 5031 & 975 & ATG & TAA & & $\mathrm{H}$ & 9 \\
\hline tRNA & 5032 & 5103 & 72 & & & GAT & $\mathrm{H}$ & \\
\hline tRNA $A^{G / n}$ & 5109 & 5179 & 71 & & & TTG & $L$ & 5 \\
\hline tRNA ${ }^{\text {Met }}$ & 5179 & 5247 & 69 & & & CAT & $\mathrm{H}$ & -1 \\
\hline ND2 & 5248 & 6288 & 1041 & ATG & TAG & & $\mathrm{H}$ & \\
\hline tRNA $A^{T r p}$ & 6287 & 6362 & 76 & & & TCA & $\mathrm{H}$ & -2 \\
\hline$t R N A^{A / a}$ & 6369 & 6437 & 69 & & & TGC & L & 6 \\
\hline tRNA $A^{A s n}$ & 6441 & 6513 & 73 & & & $\mathrm{GTT}$ & L & 3 \\
\hline tRNA $A^{\text {Cys }}$ & 6515 & 6580 & 66 & & & GCA & L & 1 \\
\hline$t R N A^{T y r}$ & 6580 & 6650 & 71 & & & GTA & L & -1 \\
\hline $\operatorname{cox} 1$ & 6652 & 8202 & 1551 & GTG & AGG & & $\mathrm{H}$ & 1 \\
\hline tRNA $A^{\text {Ser }}$ & 8194 & 8268 & 75 & & & TGA & L & -9 \\
\hline$t R N A^{A s p}$ & 8271 & 8339 & 69 & & & GTC & $\mathrm{H}$ & 2 \\
\hline $\operatorname{cox} 2$ & 8341 & 9024 & 684 & ATG & TAA & & $\mathrm{H}$ & 1 \\
\hline$t R N A^{\text {Lys }}$ & 9026 & 9093 & 68 & & & TTT & $\mathrm{H}$ & 1 \\
\hline ATPase8 & 9095 & 9259 & 165 & ATG & TAA & & $\mathrm{H}$ & 1 \\
\hline ATPase6 & 9250 & 9933 & 684 & ATG & TAA & & $\mathrm{H}$ & -10 \\
\hline $\operatorname{cox} 3$ & 9933 & 10716 & 784 & ATG & $\mathrm{T}--$ & & $\mathrm{H}$ & -1 \\
\hline tRNA ${ }^{\text {Gly }}$ & 10717 & 10785 & 69 & & & TCC & $\mathrm{H}$ & \\
\hline ND3 & 10786 & 11137 & 352 & ATG & TAA & & $\mathrm{H}$ & \\
\hline tRNA $A^{\text {Arg }}$ & 11139 & 11206 & 68 & & & TCG & $\mathrm{H}$ & 1 \\
\hline$N D 4 L$ & 11207 & 11503 & 297 & ATG & TAA & & $\mathrm{H}$ & \\
\hline ND4 & 11497 & 12874 & 1378 & ATG & $\mathrm{T}--$ & & $\mathrm{H}$ & -7 \\
\hline$t R N A^{\text {His }}$ & 12875 & 12943 & 69 & & & GTG & $\mathrm{H}$ & \\
\hline tRNA ${ }^{\text {Ser }}$ & 12944 & 13010 & 67 & & & AGA & $\mathrm{H}$ & \\
\hline tRNA ${ }^{\text {Lеu }}$ & 13011 & 13081 & 71 & & & TAG & $\mathrm{H}$ & \\
\hline ND5 & 13082 & 14899 & 1818 & ATG & TAA & & $\mathrm{H}$ & \\
\hline Cytb & 14904 & 16046 & 1143 & ATG & TAA & & $\mathrm{H}$ & 4 \\
\hline$t R N A^{T h r}$ & 16050 & 16118 & 69 & & & TGT & $\mathrm{H}$ & 3 \\
\hline tRNA $A^{\text {Pro }}$ & 16119 & 16188 & 70 & & & TGG & L & \\
\hline ND6 & 16195 & 16716 & 522 & ATG & TAA & & L & 6 \\
\hline tRNA Glu & 16719 & 16786 & 68 & & & TTC & L & 2 \\
\hline
\end{tabular}

T- - means incomplete termination codon. ${ }^{+}$Negative numbers indicate overlapping nucleotides. 
have 7 overlaps in the length of 1-10 bp. These genes had four types of termination codons, including TAA, TAG, AGG and "T- -", "T- -" is the 5 ' terminal of the adjacent gene (Anderson et al. 1981). The lengths of $12 \mathrm{~S}$ rRNA and the 16S rRNA were 975bp and 1623bp. Among 13 protein-coding genes, the longest one was ND5 gene (1818 bp) and the shortest one was ATPase8 gene (165bp). And deduced 22 tRNA genes were distributed in rRNA and protein-coding genes, ranging from 66 to $76 \mathrm{bp}$ in size, and the situation was similar to other breeds of chicken in Hunan province(Yu et al. 2016; Liu et al. 2016a; Liu et al. 2016b). The D-loop region was located between tRNA ${ }^{\text {Glu }}$ and tRNA ${ }^{\text {Phe }}$ with a length of $1232 \mathrm{bp}$. The putative origin for light strand replication (OLR) had been identified in the tRNA ${ }^{\text {Trp }}$ tRNA ${ }^{\text {Ala }}$-tRNA $A^{\text {Asn }}$-tRNA ${ }^{\text {Cys_tRNA }}{ }^{\text {Tyr }}$ region (WANCY) of most vertebrates (Lin et al. 2016b; Wang et al. 2008). However, DYC might be associated with the deletion of OLR between tRNA $A^{\text {Asn }}$ and tRNA ${ }^{\text {cys }}$ genes, which cannot be folded into a OLR-like secondary structure.

An $\mathrm{N}$-J tree showed that the analyzed species are divided into three major clades: Phasianidae, Numidiidae and Odontophoridae, moreover, the outgroup, Anseranser, is located at the base of the tree (Figure 1). Phasianidae makesup the first lineage, which is sister to the second group, Numidiidae; Odontophoridae forms the third group and is sister to Phasianidae and Numidiidae. This N-Jtree generated from the complete mitochondrial DNA for 20 Galliformes species have basically similar topologies. Three major branches are represented: Phasianidae, Acrylliumvulturinum and Colinus virginianus. The first lineage, subfamily Phasianidae, includes species of tribes Gallus, Bambusicola, Pavo, Tetraophasis, Meleagris, Phasianus, Chrysolophus and Coturnix. Acrylliumvulturinum is the sole member of the second

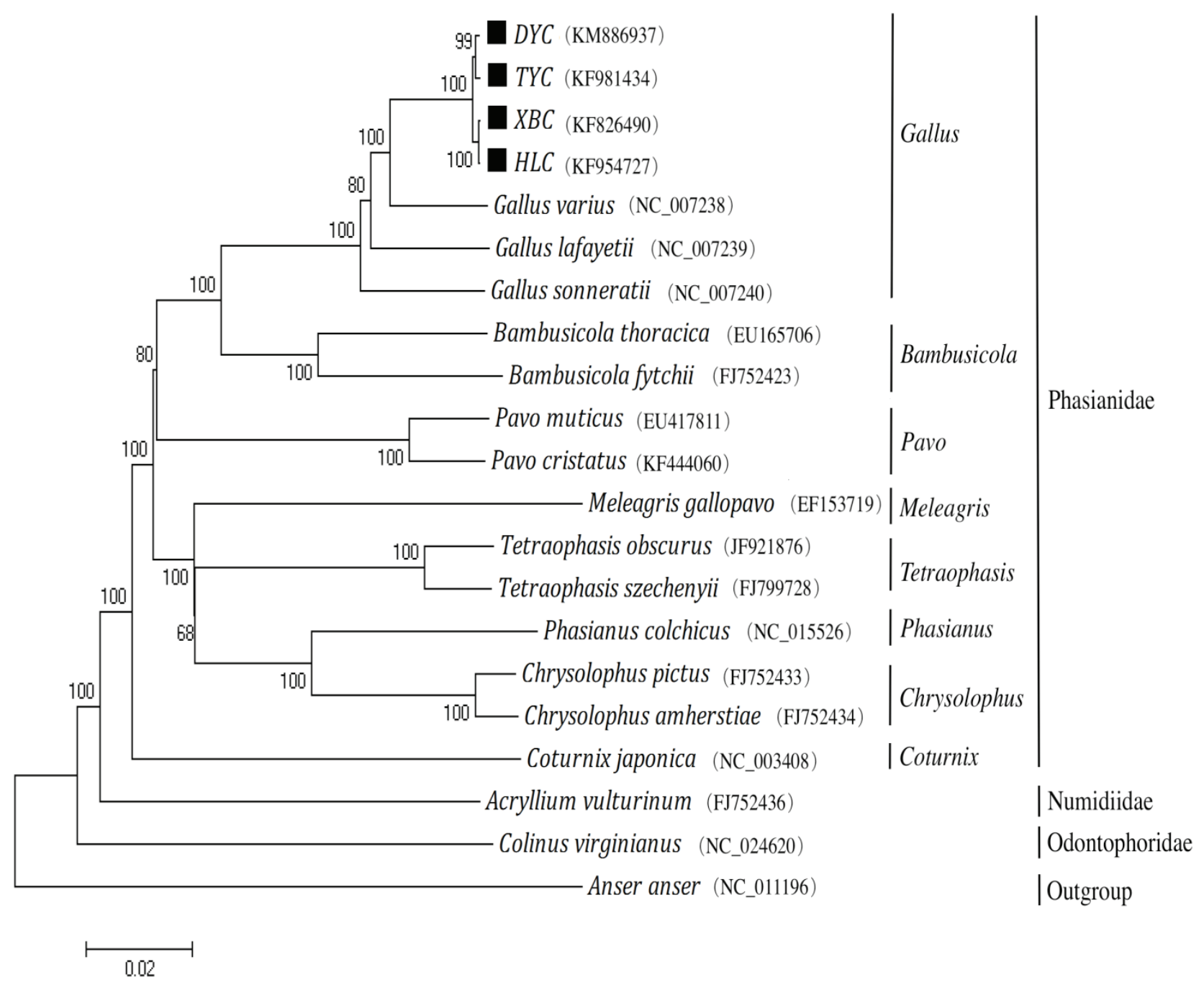

Figure 1 - Phylogenetic analysis based on complete mitochondrial genome sequences. An N-J tree was built based on the phylogenetic analysis of 20Galliformes species' complete mitochondrial genomes. The mitochondrial genome sequences of the Galliformes species were obtained from the GenBank databases (Accession numbers have marked on the figure). Abbreviation of species indicates: DYC, Donganyellow chicken; TYC, Taoyuan chicken; XBC, Xuefeng black-bonedchicken; HLC, Huang Lang chicken. 
group Numidiidae. The Phasianidae and Numidiidae are sister groups, which then group together with Colinus virginianus (Odontophoridae). Therefore, our work confirmed that DYC and TYC have a closegenetic relationship with fellow tribal members $X B C$ and HLC (The overall average genetic distance between the complete mitochondrial genome sequences is 0.127 ). Meanwhile, we also found that DYC and TYC have highly similar genetic relationship which are consistent with those reported previously (Zhao et al. 2016).

\section{ACKNOWLEDGEMENTS}

The authors report no conflicts of interest. The authors alone are responsible for the content and writing of this article. This research was supported by International S\&T Cooperation Program of China (ISTCP, 2013DFG31810) and Science \& Technology Project of Hunan Province (HHN2017SC09).

\section{REFERENCES}

Anderson S, Bankier AT, Barrell BG, de Bruijn MH, Coulson AR, Drouin J, et al. Sequence and organization of the human mitochondrial genome. Nature 1981;290(5806):457-465.
Chen K.W. Grand view of newly found local poultry varieties in China (III) China Poultry 2013;35:31-35.

Lin Q, Cao R, Jiang GT, Qiu L, Hu GB, Dai QZ, et al. The complete mitochondrial genome of the Xupu goose. Mitochondrial DNA 2016a;27(2):1010-1011.

Lin Q, Jiang GT, Cao R, Yun L, Li GJ, Dai QZ, et al. Determination and analysis of the complete mitochondrial genome sequence of Wugangtong grey goose. Mitochondrial DNA 2016b;27(2):1008-1009.

Liu LL, Xie HB, Yang YS, Yu QF, He JH. The complete mitochondrial genome of the Xuefeng black-boned chicken. Mitochondrial DNA 2016a;27(1):30-31.

Liu LL, Xie HB, Yu QF, He SP, He JH. Determination and analysis of the complete mitochondrial genome sequence of Taoyuan chicken. Mitochondrial DNA2016b;27(1):371-372.

Wang $\mathrm{CH}$, Chen Q, Lu GQ, Xu J, Yang Q, Li S Complete mitochondrial genome of the grass carp (Ctenopharyngodon idella, Teleostei): insight into its phylogenic position within Cyprinidae. Gene 2008;424(12):96-101.

Yu QF, Liu LL Fu CX, He SP, Li S, He JH. The complete mitochondrial genome of the Huang Lang chicken. Mitochondrial DNA 2016;27(1):216-217.

Zhao FP, Fan HY, Li GH, Zhang BK. Complete mitochondrial genome sequence and gene organization of Chinese indigenous chickens with phylogenetic considerations. Genetics and Molecular Research 2016;15(2):gmr. 15028200. 